\title{
A methodological guide to performing a cost-utility study comparing surgical techniques
}

\author{
Achilleas Thoma MD MSc FRCS C FACS ${ }^{1}$, Ted Haines MD MSc FRCPC ${ }^{2,3}$, Karen Veltri PhD ${ }^{1}$, \\ Charlie H Goldsmith $\mathrm{PhD}^{3,4}$, Bernie J O'Brien $\mathrm{PhD}^{3,4,5^{*}}$, Caroline Quartly MD FAAEM FRCPC 6
}

\begin{abstract}
A Thoma, T Haines, K Veltri, CH Goldsmith, BJ O'Brien, C Quartly. A methodological guide to performing a cost-utility study comparing surgical techniques. Can J Plast Surg 2004;12(4):179-187.
\end{abstract}

BACKGROUND: When recommending the adoption of a new surgical intervention as opposed to maintaining an old one, surgeons need to consider the opportunity cost, which is the value of the forgone benefits. To inform these decisions, surgeons can use economic analyses of surgical practices. Unfortunately, economic analyses conducted alongside randomized controlled trials in surgery are rare.

OBJECTIVES: The objective of the present study was to use data from a small randomized controlled trial to illustrate the methodology for a cost-utility analysis comparing two techniques of carpal tunnel release: open release without ('usual' technique) and with ('novel' technique) ligament reconstruction.

METHODS: Eighteen eligible patients were entered into this prospective study. Fifteen were followed to six weeks postoperatively. One day preoperatively, and five days, three weeks and six weeks postoperatively, patients completed a self-administered Health Utilities Index Mark 2-3 questionnaire (utilities) and a case report form from which resource utilization (cost) was collected. Utilities were expressed as quality-adjusted life weeks, a fraction of qualityadjusted life years.

RESULTS: The mean total cost of the usual technique was lower than the novel technique, and the mean quality-adjusted life week was higher, favouring the usual technique. Indirect costs were four to nine times higher than direct costs in both techniques.

CONCLUSION: The novel technique was more costly and less effective, and fell in the 'lose-lose' quadrant of the cost-effectiveness plane; it was rejected in favour of the usual technique. This methodology should be applied when deciding whether to adopt novel surgical techniques in plastic surgery to optimize scarce health care resources.

Key Words: Comparison of surgical techniques; Cost-utility analysis; Methodology

$\mathrm{T}$ he ideal cost-effectiveness (or cost-utility) study is one in which the investigators 'piggy-back' an economic evaluation to a randomized controlled trial comparing the 'novel' to the 'usual' technique of surgery. Unfortunately, such studies are uncommon in surgery because few surgeons have the necessary training to undertake them. The purpose of the present paper

\section{Un guide méthodologique pour effectuer une étude coût-utilité comparant les techniques chirurgicales}

HISTORIQUE : Au moment de recommander l'adoption d'une nou-
velle intervention chirurgicale au lieu de conserver une ancienne inter-
vention, les chirurgiens doivent tenir compte du coût de renonciation,
qui correspond à la valeur des avantages auxquels ils renoncent. Pour
étayer leurs décisions, les chirurgiens peuvent utiliser des analyses
économiques des pratiques chirurgicales. Malheureusement, les analyses
économiques menées conjointement avec des essais aléatoires et con-
trôlés sont rares.
OBJECTIFS : La présente étude visait à utiliser les données d'un petit
essai aléatoire et contrôlé pour illustrer la méthodologie d'une analyse
coût-utilité comparant deux techniques de libération du tunnel du canal
carpien : une libération ouverte sans (la technique « habituelle») et avec
(la «nouvelle " technique) reconstruction ligamentaire. MÉTHODOLOGIE : Dix-huit patients admissibles ont participé à cette étude prospective. Quinze ont été suivis jusqu'à six semaines après l'opération. Un jour avant l'opération, puis cinq jours, trois semaines et six semaines après l'opération, les patients ont rempli eux-mêmes un questionnaire Health Utilities Index Mark 2-3 (utilité) et un formulaire de rapport de cas à partir duquel l'utilisation des ressources (coût) a été colligée. L'utilité était exprimée selon le nombre de semaines-personnes sans invalidité, une fraction des années-personnes sans invalidité.

RÉSULTATS : Le coût total moyen de la technique habituelle était inférieur à celui de la nouvelle technique, et les semaines-personnes moyennes sans invalidité étaient plus élevées, ce qui favorisait la technique habituelle. Dans les deux techniques, les coûts indirects étaient de quatre à neuf fois plus élevés que les coûts directs.

CONCLUSION : La nouvelle technique était plus coûteuse et moins efficace, et se classait dans le quadrant de double contrainte des régimes coût-efficacité. Elle a donc été rejetée en faveur de la technique habituelle. Cette méthodologie devrait être appliquée au moment de décider s'il est préférable d'adopter une nouvelle technique chirurgicale en chirurgie plastique, afin d'optimiser des ressources de santé limitées.

\footnotetext{
${ }^{1}$ Department of Surgery, Division of Plastic and Reconstructive Surgery, St Joseph's Healthcare, Surgical Outcomes Research Centre (SOURCE) and McMaster University; ${ }^{2}$ Occupational Health Program, Health Sciences Centre, McMaster University; ${ }^{3}$ Department of Clinical Epidemiology and Biostatistics, McMaster University and Centre For Evaluation of Medicine; ${ }^{4}$ Father Sean O'Sullivan Research Centre, St Joseph's Healthcare; ${ }^{5}$ Centre for Health Economics and Policy Analysis, Department of Clinical Epidemiology and Biostatistics, McMaster University and Centre For Evaluation of Medicine, Father Sean O'Sullivan Research Centre, St Joseph's Healthcare, Hamilton; ${ }^{6}$ Department of Medicine, Division of Physical Medicine and Rehabilitation, McMaster University, Hamilton, Ontario. *Deceased
}

Correspondence: Dr Achilleas Thoma, 206 James Street South, Suite 101, Hamilton, Ontario L8P 3A9. Telephone 905-523-0019,

fax 905-523-0229, e-mail athoma@mcmaster.ca 
techniques of carpal tunnel release were used. The 'mock' question the authors intended to address was "Is open carpal tunnel release with Z-plasty ligament reconstruction (novel technique) more cost-effective than the usual open carpal tunnel release?"

The outcome of surgery can be measured in quality-adjusted life years (QALYs) (or a fraction of it, quality-adjusted life weeks [QALWs], if the outcome is measured in weeks) (1). QALYs can be computed from utilities. Utilities can be obtained using the Health Utilities Index (HUI) Mark 2-3 questionnaire (2-4), a well-known health status and quality of life assessment instrument developed as a simple method of measuring utilities (preferences) in clinical trials and other studies. The HUI Mark 3 is comprised of eight attributes (or dimensions) which include vision, hearing, speech, ambulation, dexterity, emotion, cognition and pain, with five to six levels per attribute (2-4). The levels range from highly impaired to normal. The utilities obtained by the administration of the HUI to patients allows one to perform a cost-utility analysis (2-4).

The second characteristic that is necessary for the performance of a cost-utility analysis is the accurate identification of costs associated with the surgeries. This requires resource utilization information. This can be obtained from a generic case report form (CRF) or one that has been modified specifically for a particular study. CRFs usually are self-administered by the patients at various time intervals before and after surgery. The CRFs usually document the following: patient and caregiver demographics; educational and employment information; use of health care resources such as visits to family doctors, occupational or physical therapists, surgeons, walk-in clinics, emergency departments, pain clinics and visits from home care as a result of surgery; patient expenses related to medications and out-of-pocket transportation costs to receive additional medical care; information related to patient and caregiver days off work; and productivity costs. Generally, only types and frequencies of resources are collected rather than costs. Only resources related to the patients' surgical intervention are collected.

Most hand surgeons would agree that the definitive treatment of carpal tunnel syndrome is carpal tunnel release. Since its first description (5), open section of the flexor retinaculum has been considered the definitive procedure; this procedure was popularized by Phalen (6) in the 1950s. The success of carpal tunnel release is high, with $84 \%$ patient satisfaction (7). Given that scar tenderness is one of the main drawbacks (8), various techniques have been introduced to minimize this complication $(7,9,10)$.

Only three studies (11-13) have used critical economic evaluation, and these compared the controversial endoscopic release technique to the open technique. Of these, only the study by Chung et al (13) was a full economic evaluation because they compared costs and effectiveness in an incremental fashion. Because the authors relied on previous studies to obtain the probabilities of the various health states associated with the two techniques, a decision analytical model was used. The weaknesses of this model in comparing the cost-effectiveness (cost-utility) analysis between the two techniques, however, were that: it relied on previous studies for the probabilities of important health states (complications) and utilities associated with these clinically important health states were derived from experts rather than patients. If probabilities of health states are instead derived from randomized controlled trials, they more closely approximate the truth compared with studies of weaker evidence (ie, retrospective studies).

Furthermore, a weakness of the deterministic analysis using the decision analytic model is the difficulty in estimating the costs of the two procedures. Whereas direct medical costs (ie, surgeons' fees, hospital fees) can be easily estimated from hospital budgeting or finance departments and third party payers, indirect costs (ie, productivity costs) are more problematic. This may not be an issue if a limited perspective such as a hospital or a third party payer is used, but it becomes important if a societal perspective is used.

For the purpose of the present study, the supposedly superior novel technique described by Jakab et al (14) (whereby the carpal ligament is reconstructed in an elongated way after open release) was compared with the usual open carpal tunnel release technique without ligament reconstruction.

\section{METHOD}

Actual data from a small sample randomized controlled trial (pilot study) were used to perform a 'mock' cost-utility study comparing the conventional open (usual) technique with the novel technique of ligament reconstruction.

\section{Patient selection}

All patients with the presumptive diagnosis of carpal tunnel syndrome seen in the practice of one of the authors (AT) between January 20, 2000, and February 21, 2000, were screened at the initial consultation. If the clinical diagnosis of carpal tunnel syndrome was made and confirmed with electromyography and nerve conduction studies, patients were invited to participate in a randomized study comparing two techniques of open carpal tunnel release.

As a result of the stringent inclusion and exclusion criteria described in Table 1, 18 of the 23 patients were eligible. Three patients did not complete the final questionnaire (one questionnaire was incomplete, one patient had language difficulty and one patient decided not to participate in the study). Thus, 15 of these 18 patients were followed to six weeks postoperatively, the end point for this pilot study. The reasons for the exclusions are listed in Table 1. A research assistant discussed the study with subjects and an informed consent for participating in the study was obtained. Approval for this study was obtained from the Ethics Review Board of St Joseph's Healthcare, Hamilton, Ontario (a McMaster University teaching hospital), in addition to the regular consent for surgery.

\section{Surgical techniques}

The conventional open surgical release of the carpal ligament involved a curvilinear palmar incision made over the carpal tunnel (15). The transverse carpal ligament was incised in a longitudinal fashion, thus, decompressing the median nerve. The comparator technique involving transection with ligament reconstruction began with a skin incision similar to the conventional open release technique. The difference between these techniques was in the way the transverse carpal ligament was managed. The ligament was incised such that two flaps were formed from the ligament: a radially based distal flap and an ulnarly based proximal flap as described by Jakab et al (14). The two flaps were then sutured together with 4-0 Vicryl suture (Ethicon Inc, USA), such that the ligament was reconstructed after its release but in 
TABLE 1

\section{Inclusion and exclusion criteria}

\begin{tabular}{l} 
Inclusion criteria \\
Daily hand numbness/paresthesia or, \\
Hand weakness or, \\
Positive Phalen's test/Tinel sign, \\
AND \\
Willingness to have surgery within study timeframe \\
Positive electromyography/nerve conduction studies \\
Exclusion criteria \\
Pregnancy \\
Diabetes \\
Previous wrist surgery including carpal tunnel release \\
General peripheral neuropathy \\
Anatomical wrist abnormalities \\
Raynaud's syndrome \\
Arthritis \\
Lack of medical fitness for surgery \\
Total patient intake: 23 \\
Total patients excluded: 5 \\
Reasons for exclusion \\
Lack of medical fitness for surgery (heart problems) \\
Diabetes \\
Surgery requested beyond time frame of study \\
Previous wrist surgery \\
Arthritis in basal joints \\
\hline
\end{tabular}

an elongated way to ensure that the median nerve was no longer compressed.

\section{Randomization and blinding}

Randomization was provided by the Surgical Outcomes Research Centre (SOURCE) using computer-generated random numbers. The surgeon was informed of which technique to use by a phone call to SOURCE $5 \mathrm{~min}$ before surgery, thus concealing the allocation from the surgeon until immediately before the surgery. The surgery was performed under local anesthesia at St Joseph's Healthcare in the day surgery unit (DSU), a less formal operating room environment than the main operating room. The patient and hand therapists were blinded as to the technique chosen because the scars were identical.

\section{Outcome measurement instrument (HUI)}

Utility values were obtained from the HUI Mark 2-3 (2-4) (with a one-week recall), which was self-administered by all patients one day before surgery (baseline, Time 1). The same questionnaire was also completed at five days (Time 2, with a two-day recall), three weeks (Time 3, with a one-week recall) and six weeks (Time 4 , with a one-week recall) after surgery.

Effectiveness and calculation of QALYs and QALWs from HUI utility score

When comparing carpal tunnel surgical techniques or most plastic surgical procedures, mortality was not an issue. The outcome of interest was patient quality of life; therefore, the measure of the effectiveness of each technique was expressed as QALYs.

In this pilot randomized controlled trial, QALWs, a fraction of the QALYs, were reported as the end point of the study because of the six-week follow-up (Time 4). The six-week follow-up was

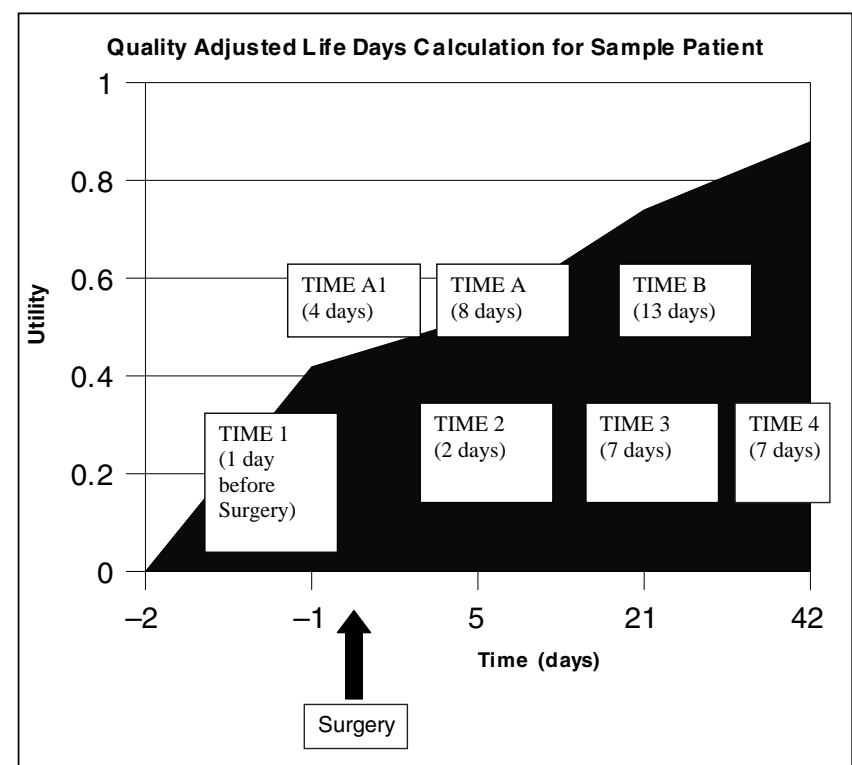

Figure 1) Graphical depiction of quality-adjusted life days calculation for sample patient \#14

considered to be the usual interval after which most patients resumed their usual activities following carpal tunnel release $(10,12)$. Utility values, transformed into QALYs and QALWs (with means and variances), in the conventional (usual) open release and comparator reconstruction technique (novel) group were obtained from the HUI Mark 2-3 questionnaire (2-4). By converting the effectiveness data to a common unit of measure such as QALWs gained, the cost-utility analysis was able to incorporate the increase in quality of life or reduced morbidity.

An example of the calculation of QALYs for sample patient \#14 is shown in Appendix 1 and the transformation of QALYs into quality-adjusted life days (QALDs) and QALWs is shown in Appendix 1A. The associated graphical depiction is shown in Figure 1.

Outcome measurement instrument (resource utilization) Resource utilization was collected from a modified CRF designed to collect information on resource utilization related specifically to carpal tunnel syndrome. The modified CRF was self-administered by patients one day before surgery (baseline, Time 1), and five days (Time 2), three weeks (Time 3 ) and six weeks (Time 4) after surgery. A sample of the modified CRF used in the study can be provided on request.

\section{Outcome measurement (grip strength)}

Grip strength of each hand was measured using the Jamar dynamometer (Model 2, Asimow Engr Co, USA), a validated instrument $(16,17)$, on the second setting as recommended by Baxter-Petralia (18). Subjects were tested for grip strength three consecutive times and a mean of the three measurements was used. Instructions and administration of these assessments were standardized. These measurements were used as a secondary outcome. Measurements were obtained at the following times: one day before surgery, and three weeks and six weeks after surgery. 
TABLE 2

Guidelines for using clinical and economic evaluations

\begin{tabular}{lll}
\hline & Effectiveness & Cost \\
\hline Grade A & More effective & Less \\
Grade B & Less than $\$ 20,000 /$ QALY & Greater \\
Grade C & $\$ 20,000$ to $\$ 100,000 / Q A L Y$ & Greater \\
Grade D & Greater than $\$ 100,000 / Q A L Y$ & Greater \\
Grade E & Less or equal effectiveness & Greater \\
\hline
\end{tabular}

QALY Quality-adjusted life year

\section{Perspective}

Because it was possible to collect sampled data from this study, in addition to the Ministry of Health perspective, a societal perspective was used as recommended by the Panel on Cost-Effectiveness in Health and Medicine (19). Society bears both direct medical costs as well as indirect costs of 'time off work'.

A cost-utility analysis was possible for this study; both the costs and effects were estimated from sampled data from the same patients. The sample variance in such a case can be used to analyze the variation in incremental cost-utility ratio. Costs were reported in 1999 Canadian dollars. According to the maximum exchange rate in 1999, US\$1 equalled Can\$1.5475 (20).

\section{Calculation of incremental cost-utility ratio}

In health economic evaluations where normally the novel surgical procedure is more effective but more costly, it was recommended that the incremental cost-utility ratio (ICUR) be calculated as follows:

\begin{tabular}{|c|c|c|}
\hline ICUR = & $\Delta \mathrm{C}=$ & Mean cost ${ }_{\text {novel }}-$ Mean cost ${ }_{\text {usual }}$ \\
\hline & $\overline{\Delta U}$ & $\overline{\text { Mean QALWs }}$ novel - Mean QALWs usual \\
\hline
\end{tabular}

where $\Delta \mathrm{C}$ and $\Delta \mathrm{U}$ were increments of costs and utilities, respectively.

\section{Deciding whether to adopt or reject the novel surgical technique}

To warrant adoption of a novel medical intervention, Laupacis et al (21) introduced five grades of recommendation based on the magnitude of its incremental net benefit (Table 2). Grade A classification referred to a more effective and less costly novel technique whereas Grade E referred to a novel technique that provided less or equal effectiveness at a greater cost. Grades B, C and $\mathrm{D}$ referred to a novel technique that was more effective and more costly, with a Grade B technique costing less than $\$ 20,000 / \mathrm{QALY}$, a Grade C technique corresponding to a cost between $\$ 20,000$ and $\$ 100,000 /$ QALY and Grade D costing more than $\$ 100,000 /$ QALY (21).

Preliminary calculations of $\Delta \mathrm{C}$ and $\Delta \mathrm{U}$ were performed, followed by the determination of the point estimate on the cost-effectiveness plane. This determined whether it was necessary to calculate the ICUR. If the comparator novel technique was more costly and less effective than the usual technique (as in the present study), the ICUR calculation was not necessary because the novel procedure was dominated by the usual open technique.

\section{Costs}

The validity of the cost-effectiveness analysis depended to a great extent on the accurate estimation of the costs (22). There were various costs associated with the two open surgical techniques in the present study. Direct medical costs included the actual costs in resource use, attributable to the surgical interventions performed in this study, and the indirect costs were associated with patient and caregiver expenses.

Direct medical costs: The costs identified in this study were classified as physician fees, hospital costs and physiotherapy costs. In 1999, the physician payment for carpal tunnel release in Ontario was $\$ 144$ (23). This fee was the same for either conventional release (usual technique) without reconstruction or the comparator (reconstruction) technique used in this study. That is, the surgeon was not reimbursed for the additional effort of reconstructing the ligament. In Ontario as well as the other provinces, the health cost was calculated on a per diem basis. The variable direct cost of one procedure in the DSU at St Joseph's Healthcare, with an average time of half an hour, was $\$ 87.82$. (Breakdown: salaries $\$ 75.82$, drugs and medicines $\$ 2.55$, trays and general supplies $\$ 1.12$, depreciation \$3.06). The fully loaded (overhead included) cost was $\$ 123.56$. The cost of a registered step 8 nurse was $\$ 37.42 / \mathrm{h}$ (US\$28.13/h).

The differential cost between the two techniques was estimated by recording the time the surgery started from the first incision to the placement of the last suture for each patient. This was recorded in the CRF. This allowed an estimation of the differential cost in utilizing the DSU procedure room and nursing time. The reconstruction technique utilized an extra suture of 4-0 Vicryl at a cost of $\$ 3.88$ /suture. Both surgical interventions used the same volume of local anesthetic and other supplies.

If a major complication was to occur and the patient required additional surgery, this would have taken place in the main operating room. The costs in such a case would have been calculated appropriately from data obtained from the budgeting department at St Joseph's Healthcare. The variable cost in using the main operating room was $\$ 496.72 / \mathrm{h}$ and the fully loaded cost (including overhead) was $\$ 659 / \mathrm{h}$. The variable cost was used in the analyses. None of the study patients required this additional procedure.

The physiotherapy costs included the initial consultation fee of $\$ 30.00$ and subsequent visits valued at $\$ 12.20 /$ visit. The total costs were estimated by multiplying the number of visits to physiotherapy by the cost of each visit up to six weeks (which was taken as the cut-off of the study). For the purpose of the present study, the study authors only considered Ontario Health Insurance Plan fees.

Indirect medical costs: In taking a societal perspective of cost calculations, patients were asked to record on the CRFs (in addition to visits to their family doctors, emergency room or walk-in clinics) their out-of-pocket expenses; in particular, the purchase of pain medications. In general, if the patients already had pain pills at home for previous doctor visits, no pills were prescribed. However, patients were asked to note the pills they had taken. If they had no pills at home, a prescription of Tylenol \#3 or \#2 (JanssenOrtho/McNeil Consumer Healthcare, Canada) (20 tablets) was given and they were again instructed to report the number of pills taken.

Productivity costs: Indirect (productivity) costs were earnings lost by patients and caregivers as a result of the surgery. These were calculated by the Human Capital method (24-28). The time off work for the patient and the caregiver was noted and the number of days off work were multiplied by the average daily wage rate for Ontario in 1999 (\$133) (29). This productivity cost was included only in the numerator of the ICUR to avoid double counting. In a small pilot randomized controlled trial such as this, the inclusion of patient-specific earnings may have confounded the results if by 
TABLE 3

Costs, quality-adjusted life weeks (QALWs), quality-adjusted life years (QALYs) and utilities for Health Utilities Index Mark 3 at six weeks follow-up (Time 4) for patients with no ligament reconstruction

\begin{tabular}{|c|c|c|c|c|c|c|c|}
\hline \multirow[b]{2}{*}{ Patient } & \multirow[b]{2}{*}{ Age (years) } & \multicolumn{5}{|c|}{ No ligament reconstruction (usual) $(n=6)$} & \multirow[b]{2}{*}{ Utility } \\
\hline & & Total cost (\$) & Indirect cost (\$) & Direct cost (\$) & QALW & QALY & \\
\hline 10 & 39 & 1275.83 & 1074.40 & 201.43 & 5.005 & 39.600 & 1.000 \\
\hline 11 & 52 & 513.37 & 144.79 & 368.58 & 4.494 & 26.563 & 0.692 \\
\hline 12 & 53 & 4504.33 & 4247.30 & 257.03 & 4.803 & 25.586 & 0.879 \\
\hline 13 & 49 & 202.84 & 12.06 & 190.78 & 4.734 & 29.597 & 0.973 \\
\hline 14 & 42 & 3252.17 & 3064.94 & 187.23 & 4.266 & 36.586 & 0.879 \\
\hline 15 & 42 & 1261.35 & 941.42 & 319.93 & 1.383 & 36.532 & 0.430 \\
\hline Mean & 46.0 & 1834.98 & 1580.82 & 254.16 & 4.114 & 32.411 & 0.80887 \\
\hline $\mathrm{SD}$ & 5.9 & 1684.40 & 1703.01 & 75.77 & 1.362 & 5.913 & 0.215 \\
\hline SE & 2.4 & 687.66 & 695.25 & 30.93 & 0.556 & 2.413 & 0.088 \\
\hline Minimum & 39 & 202.84 & 12.06 & 187.23 & 1.383 & 25.586 & 0.430 \\
\hline Maximum & 53 & 4504.33 & 4247.30 & 368.58 & 5.005 & 39.600 & 1.000 \\
\hline
\end{tabular}

TABLE 4

Costs, quality-adjusted life weeks (QALWs), quality-adjusted life years (QALYs) and utilities for Health Utilities Index Mark 3 at six weeks follow-up (Time 4) for patients with 'novel' ligament reconstruction

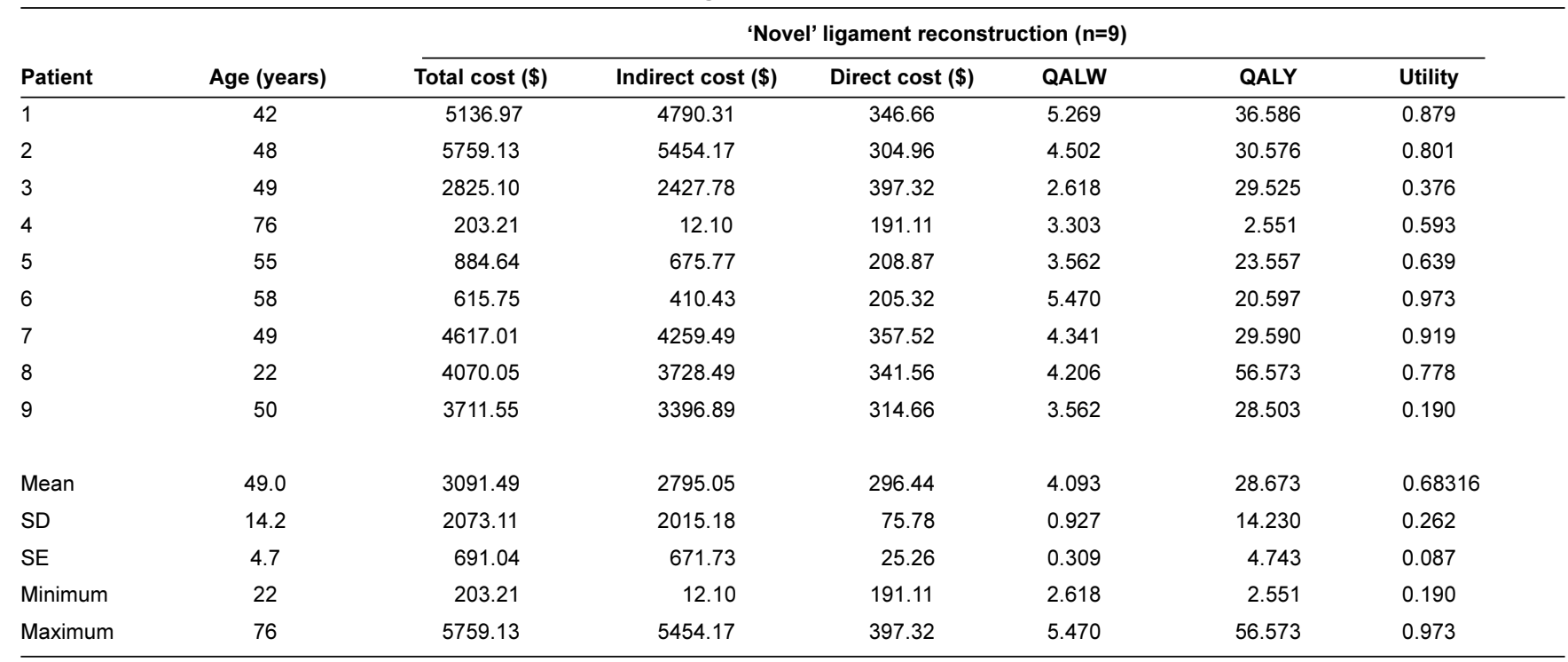

chance a wealthy patient was included in one group, thus acting as an outlier. For this reason, the average Canadian industrial aggregate weekly wage rate of $\$ 605.24$ (based on a 36.4 h work week) was used in the calculation of the productivity cost (29). For the caregivers, the opportunity cost of $\$ 605.24 / 36.4$ h work week was used (29). The following assumptions were made: a work day equalled $8 \mathrm{~h}$; and if an employed caregiver of a patient had lost time from work, the caregiver's lost earnings were considered in addition to the patient's lost earnings.

\section{RESULTS}

From a sample of 15 eligible patients, six received the usual release without ligament reconstruction (four women, two men). This group had a mean age of 46 years (minimum 39 years; maximum 53 years) (Table 3 ). Nine patients (five women, four men) received the novel technique with ligament reconstruction. The mean age for this group was 49 years (minimum 22 years; maximum 76 years) (Table 4 ).

The direct, indirect, total and incremental costs of the two procedures are shown in Table 5. In Table 3, the mean total cost per patient for the usual technique was $\$ 1834.98$ with a mean effectiveness of 4.114 QALW over six weeks. The mean total cost of the novel technique was $\$ 3091.49$ with a mean effectiveness of 4.093 QALW (Table 4). The difference in total cost was $\$ 1256.51$ less for the usual release, and this technique provided a gain in QALWs of 0.021 compared with the novel technique.

An ICUR calculation was not appropriate in this case because the novel technique was dominated by the usual technique. The novel technique fell into the lose-lose quadrant of 
TABLE 5

Direct, indirect and total cost (means) at six-week follow-up (Time 4)

\begin{tabular}{|c|c|c|c|}
\hline & Novel technique $(n=9)$ & Usual technique $(n=6)$ & Difference (novel - usual) \\
\hline \multicolumn{4}{|l|}{ Ministry of Health perspective } \\
\hline \multicolumn{4}{|l|}{ Mean direct cost } \\
\hline DSU: Mean length of surgery, min & 14.22 & 10.25 & 3.97 \\
\hline Mean nursing cost/patient & $\$ 8.87$ & $\$ 6.39$ & $\$ 2.48$ \\
\hline Mean suture cost/patient & $\$ 8.05$ & $\$ 4.17$ & $\$ 3.88$ \\
\hline Total direct cost (mean \pm SD) & $\$ 296.44 \pm 75.77$ & $\$ 254.16 \pm 75.77$ & Mean difference $=\$ 42.28$ \\
\hline \multicolumn{4}{|l|}{ Societal perspective } \\
\hline \multicolumn{4}{|l|}{ Mean indirect cost } \\
\hline Medications: Mean number of pills & 6 & 6 & 0 \\
\hline Mean medication cost/patient & $\$ 12.18$ & $\$ 10.20$ & $\$ 1.98$ \\
\hline Mean caregiver lost earnings & $\$ 158.99$ & $\$ 110.61$ & $\$ 48.38$ \\
\hline Total indirect cost (mean \pm SD) & $\$ 2795.05 \pm 2015.18$ & $\$ 1580.82 \pm 1703.01$ & Mean difference $=\$ 1214.23$ \\
\hline Total cost (direct plus indirect) (mean $\pm \mathrm{SD}$ ) & $\$ 3091.49 \pm 2073.11$ & $\$ 1834.98 \pm 1684.40$ & Mean difference $=\$ 1256.51$ \\
\hline
\end{tabular}

DSU Day surgery unit

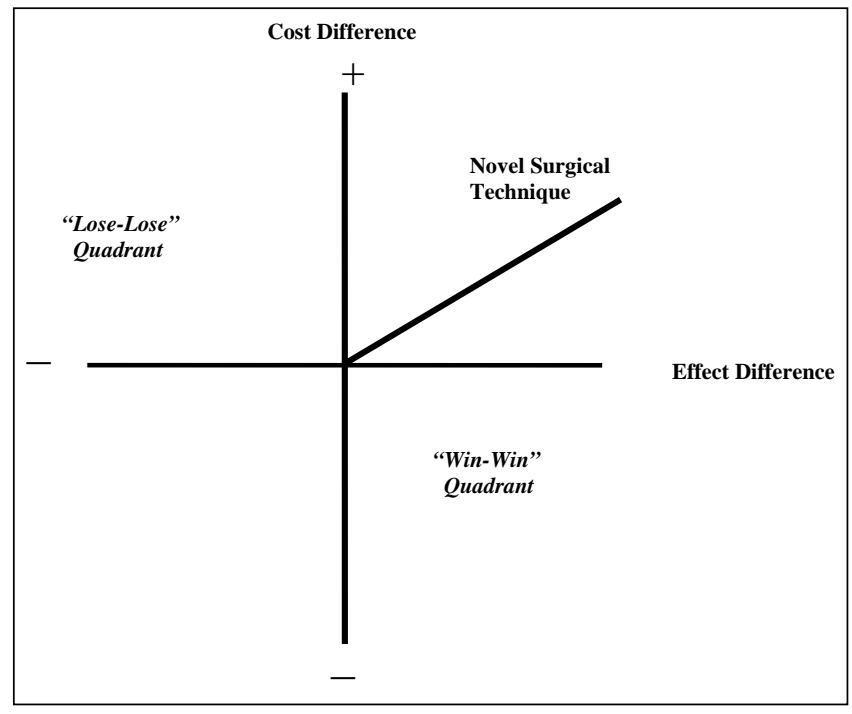

Figure 2) Cost-effectiveness plane

the cost-effectiveness plane (Figure 2). There were four quadrants representing different conclusions for the surgical release techniques described. If a technique provided a gain in QALWs at a lower cost, the ICUR would fall into the 'winwin' (bottom right) quadrant of the cost-effectiveness plane (Figure 2), providing evidence to adopt this technique. If a technique provided fewer QALWs at a higher cost, the ICUR would fall into the lose-lose quadrant (upper left) favouring rejection of the technique. If the technique provided more QALWs at a higher cost, it would fall in the upper right quadrant. If the technique was less costly with fewer QALWs, the ICUR would fall within the bottom left quadrant. If the results fell into the latter two quadrants, the magnitude of the ICUR would become an important deciding factor whether to accept or reject the technique.

By using only the direct medical costs in the calculations, the mean direct cost of the reconstruction technique was $\$ 296.44$ with a mean QALW of 4.093 (Table 4). With the usual release, the direct cost was $\$ 254.16$ with a mean QALW of 4.114 (Table 3). Therefore, the usual release was again less costly than the reconstruction technique with a difference of $\$ 42.28$ (Table 5). The indirect cost was four to nine times higher than the direct cost.

Table 6 lists the mean grip strength of patients receiving either the usual technique or the novel technique. With the large variance in grip strength with both techniques, no meaningful conclusion could be reached from these pilot data.

\section{DISCUSSION}

Due to a large variance in both the costs and the utilities, the small sample of 15 patients for this 'mock trial' was inadequate for statistical analysis. As expected, no recommendation can be made on the benefit of the carpal ligament reconstruction technique until a larger study is undertaken to answer the question. It was simply used here to provide actual data to emphasize the methodology of a cost-utility analysis.

The magnitude of the difference between the indirect and direct costs in either technique was impressive. The total cost associated with the usual release, for example, was $\$ 1834.98$ and from this, the direct cost accounted for $\$ 254.16$ (for the novel technique, the values were $\$ 3091.49$ and $\$ 296.44$, respectively). Notably, the indirect costs were four to nine times higher than the direct costs in both techniques. If a narrower perspective was undertaken, such as the hospital or the Ministry of Health, the true costs of the two techniques would have been underestimated. Most economic 
TABLE 6

Preoperative and postoperative (six weeks) grip strength in the affected hand of patients receiving 'usual' open release or open release with immediate ligament reconstruction ('novel')

\begin{tabular}{|c|c|c|c|c|}
\hline & \multicolumn{4}{|c|}{ Affected hand grip strength (kg) } \\
\hline & \multicolumn{2}{|c|}{ Left hand } & \multicolumn{2}{|c|}{ Right hand } \\
\hline & Usual & Novel & Usual & Novel \\
\hline \multicolumn{5}{|l|}{ Preoperative } \\
\hline $\mathrm{n}$ & 2 & 4 & 4 & 5 \\
\hline Mean \pm SD & $26.34 \pm 1.89$ & $24.79 \pm 11.06$ & $27.84 \pm 10.37$ & $12.77 \pm 7.59$ \\
\hline Minimum & 25.00 & 11.67 & 20.67 & 3.67 \\
\hline Maximum & 27.67 & 38.50 & 43.00 & 20.00 \\
\hline \multicolumn{5}{|c|}{ Postoperative (six weeks) } \\
\hline $\mathrm{n}$ & 2 & 4 & 4 & 5 \\
\hline Mean \pm SD & $20.50 \pm 2.59$ & $12.92 \pm 13.39$ & $22.71 \pm 4.58$ & $9.58 \pm 6.01$ \\
\hline Minimum & 18.67 & 5.67 & 17.67 & 0.57 \\
\hline Maximum & 22.33 & 33.00 & 26.83 & 17.00 \\
\hline
\end{tabular}

analyses reported in the surgical literature are of limited use because they compare only direct medical costs. Whenever possible, the broader viewpoint of society should be considered in estimating the true costs of plastic surgery procedures.

There is some controversy as to whether QALYs are the best measure for the outcomes in cost-utility analyses. Some investigators reject the QALY model because it seems to discriminate against the elderly or the sick (30). Others suggest other outcome measures such as 'healthy year equivalents' (31-33), 'save young life equivalents' (34) or the 'disabilityadjusted life years' (35). At present, however, QALYs are the most widely accepted outcome measure.

Another important controversy is whether 'experts' (ie, surgeons), the public or patients should be used to evaluate health states (ie, to yield utility values) $(22,36,37)$. The utilities for this study were estimated by the validated, self-administered HUI 2-3 questionnaire. It is generally recommended by health economists that utilities be obtained from patients themselves, as was done in this study (37).

As a consequence for the present study, QALWs over a six-week period were used. Others have used 'days until return to work' for the analysis when comparing different techniques of carpal tunnel release (12). The effectiveness of a plastic surgery procedure can be measured in terms of lives saved (eg, burns), limbs saved (eg, microsurgery) and days off work averted (eg, hand surgery), etc. Such measurement variables, however, do not permit a comparison of the benefits across different types of surgical procedures, for example, coronary bypass versus carpal tunnel release. By converting the effectiveness data to a common unit of measure such as QALYs gained (using the HUI), cost-utility analysis can incorporate the increase in the quality of life or reduced morbidity. Third party payers such as the Ministry of Health would favour this type of presentation of effectiveness because the Ministry must decide where to allocate scarce health care resources $(22,38)$.

Because the mean time to return to work is the measure for effectiveness (consequence) that is used in some publications (although it may be unreliable due to other factors that affect the return to work), it may be advisable to use both measures rather than just QALYs in a future large scale randomized controlled trial. If the outcome measure is days off work then the study will be labelled as a cost-effectiveness analysis. If QALYs are used as the outcome, the study will be labelled as a cost-utility analysis (22).

Results from this pilot randomized controlled trial indicate that it is feasible to use the HUI to capture utilities and a CRF to capture resource utilization. The methodology described in this pilot study can be used to perform a cost-utility analysis among competing plastic surgery techniques. The introduction of a novel plastic surgery technique is seductive. The cost-utility analysis will guide surgeons in their decision whether to adopt the novel surgical technique or continue to use the usual technique, thus optimizing the allocation of scarce health care resources.

ACKNOWLEDGEMENTS: The authors would like to thank XLTEK Ltd, Oakville, Ontario for the use of the portable electromyography machine (Neuromax) to perform electrophysiological assessments. The authors would also like to acknowledge Sheila Sprague, MSc, for formatting the final version of the manuscript.

\begin{tabular}{|c|c|}
\hline \multicolumn{2}{|c|}{$\begin{array}{c}\text { APPENDIX 1 } \\
\text { Calculation of quality-adjusted life years (QALYs) }\end{array}$} \\
\hline $\begin{array}{r}\text { Samp } \\
a\end{array}$ & $\begin{array}{l}\text { ent \#14 using data from Table } 3 \text { and } \\
\text { e life expectancy of } 78.6 \text { years }^{*}\end{array}$ \\
\hline Number of healthy & $\begin{array}{l}=\text { Life expectancy }- \text { age of patient } \# 14 \\
=78.6-42 \text { years } \\
=36.6 \text { years }\end{array}$ \\
\hline Follow-up interval & $\begin{array}{l}=\text { Number of weeks follow-up/year } \\
=\text { Six-week follow-up } / 52 \text { weeks } \\
=0.12 \text { years }\end{array}$ \\
\hline QALY & $\begin{aligned}= & (\text { Follow-up interval }) \times(\text { HUI utility at follow-up }) \\
& +(\text { number of healthy years }-0.12) \\
= & (0.12 \text { years }) \times(0.87935)+(36.48) \\
= & 36.586 \text { QALY }\end{aligned}$ \\
\hline
\end{tabular}




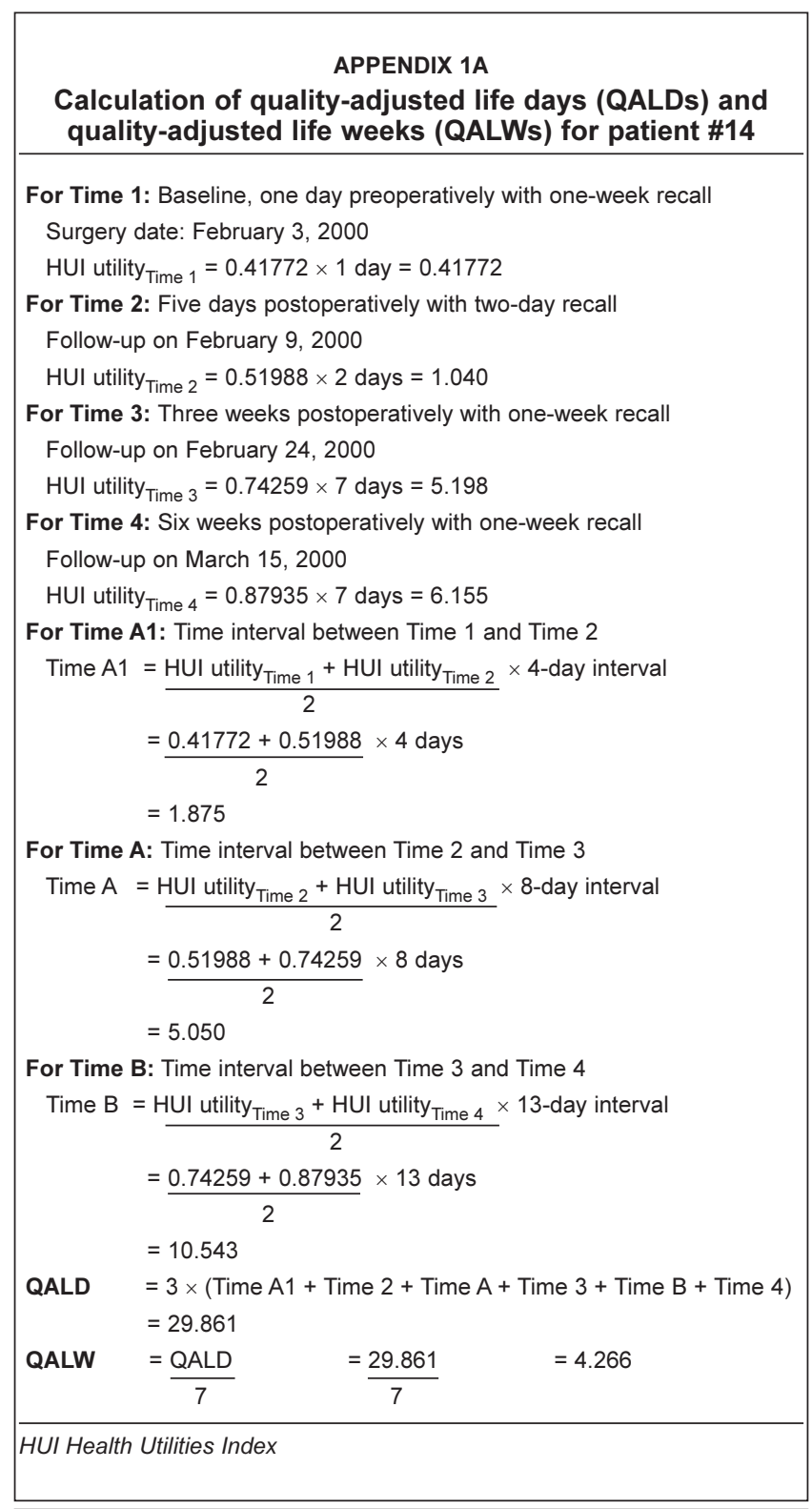

\section{Sample calculation of incremental cost utility ratio (ICUR) using pilot data from Tables 3 and 5}

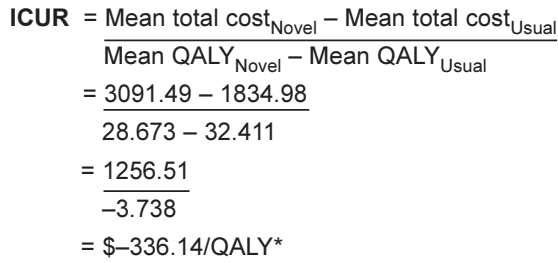

*Using the pilot study data, because the novel technique falls into the loselose' quadrant of the cost-effectiveness plane, it is not necessary to perform the calculation as above. QALY Quality-adjusted life year

\section{REFERENCES}

1. Guyatt GH, Naylor CD, Juniper E, Heyland DK, Jaeschke R, Cook DJ. Users' guides to the medical literature. XII. How to use articles about health-related quality of life. Evidence Based Medicine Working Group. JAMA 1997;277:1232-7.
2. Torrance GW, Furlong WJ, Feeny DH, Boyle M. Multi-attribute preference functions: Health utilities index. Pharmacoeconomics 1995;7:503-20.

3. Feeny D, Furlong W, Boyle M, Torrance GW. Multi-attribute health status classification systems: Health Utilities Index.

Pharmacoeconomics 1995;7:490-502.

4. Feeny DH, Torrance GW, Furlong WJ. Health utilities index. In: Spilker B, Ed. Quality of Life and Pharmacoeconomics in Clinical Trials, 2nd Edn. Philadelphia: Lippincott-Raven, 1996:239-52.

5. Learmonth JR. Treatment of diseases of peripheral nerves. Surg Clin North Am 1933;13:905-13.

6. Phalen GS. The carpal tunnel syndrome: Seventeen years' experience in diagnosis and treatment of six hundred fifty-four hands. J Bone Joint Surg Am 1966;48:211-28.

7. Brown RA, Gelberman RH, Seiler JG 3rd, et al. Carpal tunnel release. A prospective, randomized assessment of open and endoscopic methods. J Bone Joint Surg Am 1993;75:1265-75.

8. Hulsizer DL, Staebler MP, Weiss AP, Alekman E. The results of revision carpal tunnel release following previous open versus endoscopic surgery. J Hand Surg [Am] 1998;23:865-9.

9. Agee JM, McCarroll HR Jr, Tortosa RD, Berry DA, Szabo RM, Peimer CA. Endoscopic release of the carpal tunnel: A randomized prospective multicenter study. J Hand Surg [Am] 1992;17:987-95.

10. Jacobsen MB, Rahme $H$. A prospective, randomized study with an independent observer comparing open carpal tunnel release with endoscopic carpal tunnel release. J Hand Surg [Br] 1996;21:202-4.

11. Saw NL, Jones S, Shepstone L, Meyer M, Chapman PG, Logan AM. Early outcome and cost-effectiveness of endoscopic versus open carpal tunnel release: A randomized prospective trial. J Hand Surg [Br] 2003;28:444-9.

12. Vasen AP, Kuntz KM, Simmons BP, Katz JN. Open versus endoscopic carpal tunnel release: A decision analysis. J Hand Surg [Am] 1999;24:1109-17.

13. Chung KC, Walters MR, Greenfield ML, Chernew ME. Endoscopic versus open carpal tunnel release: A cost-effectiveness analysis. Plast Reconstr Surg 1998;102:1089-99.

14. Jakab E, Ganos D, Cook FW. Transverse carpal ligament reconstruction in surgery for carpal tunnel syndrome. A new technique. J Hand Surg [Am] 1991;16:202-6.

15. Taleisnik J. The palmar cutaneous branch of the median nerve and the approach to the carpal tunnel. J Bone Joint Surg Am 1973;55:1212-7.

16. Mathiowetz V, Weber K, Volland G, Kashman. Reliability and validity of grip and pinch strength evaluations. J Hand Surg [Am] 1994;9:222-6.

17. Mathiowetz V, Kashman N, Volland G, Weber K, Dowe M, Rogers S. Grip and pinch strength: Normative data for adults. Arch Phys Med Rehabil 1985;66:69-74.

18. Baxter-Petralia PL. Therapist's management of carpal tunnel syndrome. In: Hunter M, Schneider L, Mackin E, Callaghan A, eds. Rehabilitation of the Hand. Toronto: CV Mosby, 1990.

19. Weinstein MC, Siegel JE, Gold MR, Kamlet MS, Russell LB. Recommendations of the Panel on Cost-effectiveness in Health and Medicine. JAMA 1996;276:1253-8.

20. Bank of Canada, 1999. Accessed May 2, 2001. <http://www.bankofcanada.ca/en/exchange-look.htm>. (Version current at September 30, 2004).

21. Laupacis A, Feeny D, Detsky AS, Tugwell PX. How attractive does a new technology have to be to warrant adoption and utilization? Tentative guidelines for using clinical and economic evaluations. CMAJ 1992;146:473-81.

22. Drummond MF, O'Brien BJ, Stoddart GL, Torrance GW. Methods for the Economic Evaluation of Health Care Programmes, 2nd edn. New York: Oxford University Press, 1997.

23. Ontario Ministry of Health Schedule of Benefits (Physician Services Under the Health Insurance Act). Ottawa: Ministry of Health and Long-Term Care, 1998.

24. Goeree R, O'Brien BJ, Blackhouse G, Agro K, Goering P. The valuation of productivity costs due to premature mortality: A comparison of the human-capital and friction-cost methods for schizophrenia. Can J Psychiatry 1999;44:455-63.

25. Mushkin SJ, Collings FD. Economic costs of disease and injury. Public Health Rep 1959;74:795-809.

26. Rice DP. Estimating the cost of illness. Health Economics Series \#6, Publication \#947-6. Washington: US Government Printing Office, 1996. 
27. Rice DP. Estimating the costs of illness. Am J Public Health Nations Health 1967;57:424-40.

28. Koopmanschap MA, van Ineveld BM. Towards a new approach for estimating indirect costs of disease. Soc Sci Med 1992;34:1005-10.

29. Statistics Canada. Employment, Earnings and Hours. Catalogue number 72-002-XPB. Ottawa: Ministry of Industry, Science and Technology, 1999.

30. Aksoy S. Can the "quality of life" be used as a criterion in health care services? Bull Med Ethics 2000;162:19-22.

31. Mehrez A, Gafni A. Quality-adjusted life years, utility theory and healthy-years equivalents. Med Decis Making 1989;9:142-9.

32. Mehrez A, Gafni A. The healthy-years equivalents: How to measure them using the standard gamble approach. Med Decis Making 1991;11:140-6.

33. Mehrez A, Gafni A. Preference based outcome measures for economic evaluation of drug interventions: Quality adjusted life years (QALYs) versus healthy years equivalents (HYEs). Pharmacoeconomics 1992;1:338-45.
34. Nord E. Health status index models for use in resource allocation decisions: A critical review in the light of observed preferences for social choice. Int J Technol Assess Health Care 1996;12:31-44.

35. Fox-Rushby JA, Hanson K. Calculating and presenting disability adjusted life years (DALYs) in cost-effectiveness analysis. Health Policy Plan 2001;16:326-31.

36. Weeks J. Measurement of utilities and quality-adjusted survival. Oncology (Huntingt) 1995;9:67-70.

37. Gold MR, Stiegel JE, Russell CB, Weinstein MC. Cost-effectiveness in Health and Medicine. New York: Oxford University Press, 1996.

38. Thoma A, Sprague S, Tandan V. Evidence-Based Surgery Working Group. Users' guides to the surgical literature: How to use an article on economic analysis. Can J Surg 2001;44:347-54.

39. Statistics Canada. Disability-free life expectancy, provinces and territories. <http://www.statcan.ca/english/Pgdb/health38.htm> (Version current at November 15, 2004). 